\title{
SISTEMA NACIONAL DE EDUCAÇÃO, FEDERALISMO E OS OBSTÁCULOS AO DIREITO À EDUCAÇÃO BÁSICA
}

\author{
LUIZ FERNANDES DoURADo*
}

RESUMO: O texto discute os obstáculos para a efetivação do direito à educação, diante dos quais é preciso instituir o Sistema Nacional de Educação (SNE). Situa, assim, os limites do federalismo brasileiro, o marco legal e as políticas e gestão da educação, ressaltando as assimetrias no campo educacional e a revisão do pacto federativo, sob a regulamentação do regime de colaboração entre os entes federados e a coordenação federativa. Ao final, ressalta a necessidade de instituir o SNE junto aos demais sistemas de ensino, como base para a garantia ao direito à educação básica e sua democratização.

Palavra-chave: Sistema Nacional de Educação. Plano Nacional de Educação. Pacto federativo. Regime de colaboração.

\section{The National System of Education, Federalism and THE OBSTACLES TO THE RIGHT TO BASIC EDUCATION}

ABSTRACT: The text discusses the obstacles to the effective right to education, in face of which it is necessary to institute the National System of Education (SNE). Thus, it situates the limits of the Brazilian federalism, the legal framework and the educational and management policies, highlighting the asymmetries in the educational field and the reform of the federative pact, under the regulation of Intergovernmental collaboration and federal coordination. Finally, it points out the need to institute the SNE in conjunction with the other educational systems, to ensure the right to basic education and its democratization.

Key words: National System of Education. National Education Plan. Federative pact. Intergovernmental collaboration.

Faculdade de Educação da Universidade Federal de Goiás (UFG). Goiânia (GO) - Brasil.

Contato com o autor: <luizdourado1@gmail.com> 


\title{
Système National d'Éducation, FÉdÉRAlisme ET LES OBSTACLES AU DROIT À L'ÉDUCATION BASIQUE
}

\begin{abstract}
RÉSUMÉ: Le texte discute les obstacles pour la mise en action du droit à l'éducation, devant les lesquels il faut instituer le Système National d'Éducation (SNE). Il place, ainsi, les limites du fédéralisme brésilien, la borne légale et les politiques de gestion de l'éducation, en souligant les asymétries dans le domaine scolaire et la révision du pacte fédéral, conformément au règlement du régime de collaboration entre les entités fédérées et la coordination fédérale. À la fin, il souligne le besoin d'instituer le SNE près des autres systèmes d'enseignement, comme la base pour la garantie au droit à l'éducation basique et sa démocratisation.
\end{abstract}

Mots-clés: Système National d'Éducation. Plan National d’Éducation. Pacte fédératif. Régime de collaboration.

\section{Introdução}

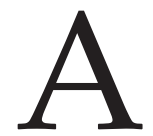

reflexão sobre as políticas educacionais e seus desdobramentos na realidade brasileira implica a necessária compreensão dos complexos processos de organização e gestão, bem como a regulamentação e a regulação que os demarcam, a relação e o regime de colaboração entre os entes federados (União, estados, Distrito Federal e municípios), as questões relativas ao acesso, qualidade, valorização profissional, financiamento e seus desdobramentos nas ações, programas e políticas direcionadas à educação.

Todas essas questões vêm sendo objeto de análises e proposições de diferentes matizes teórico-ideológicas, cuja convergência sinaliza para a importância da efetivação do Plano Nacional de Educação (PNE) como política de Estado e a institucionalização do Sistema Nacional de Educação (SNE).

Ressalte-se a aprovação de duas importantes emendas à Constituição Federal de 1988, EC n. 53/2007 e EC n. 59/2009, cujas matérias incidem diretamente no horizonte das políticas educacionais, sobretudo a educação básica. Destaque-se a importância assumida pelas conferências de educação, desde a década de 1930; retomadas com vigor com as conferências estadual e distrital, em 2009, precedidas de conferências municipais e regionais, culminaram na Conferência Nacional de Educação (Conae), ocorrida em Brasília em 2010. Ambos os movimentos sinalizam importantes conquistas para a educação brasileira, seus processos de organização e gestão e seus desdobramentos no direito à educação.

Outro marco importante é a tramitação do Plano Nacional de Educação, cujas diretrizes, metas e estratégias, em que pese um conjunto de tensões e questionamentos, sinalizam para as relações cooperativas e colaborativas entre os entes federados. Tais questões assumem grande complexidade no atual cenário da educação 
nacional, especialmente nos contornos políticos e econômicos que a engendram, em especial o fundo público, na interface entre esferas pública e privada.

O propósito deste artigo é resgatar esses movimentos, seu marco legal e seus desdobramentos na institucionalização do SNE e de novos marcos a relação federalismo e educação .

\section{Dispositivos constitucionais e direito à educação}

O Estado brasileiro é marcado por desigualdades sociais e assimetrias entre os entes federados e, por consequência, apresenta limites no horizonte de efetivação dos direitos sociais e na capilaridade das políticas, com destaque para as políticas educacionais.

A Constituição Federal (CF) de 1988 sinaliza novas diretrizes para os direitos sociais no país, tendo por eixo um novo pacto federativo. Ela estruturou a lógica política que sinaliza para a autonomia e o regime de colaboração, a ser regulamentado entre os entes federados: União, estados, Distrito Federal e municípios.

Tais questões não se dissociam de temas como reforma tributária, novo pacto federativo e efetiva descentralização das políticas (sem perder de vista a importância da coordenação nacional da União), que tenham por eixo a regulamentação do regime de colaboração. A CF de 1988, em seu artigo 23, parágrafo único, sinaliza para a necessidade de lei complementar para a fixação de normas de cooperação entre os entes federados. De acordo com o parágrafo único, a "Lei complementar fixará normas para a cooperação entre a União e os estados, o Distrito Federal e os municípios, tendo em vista o equilíbrio do desenvolvimento e do bem-estar em âmbito nacional". O parágrafo foi alterado e passou a ter a seguinte redação: "Parágrafo único. Leis complementares fixarão normas para a cooperação entre a União e os estados, o Distrito Federal e os municípios, tendo em vista o equilíbrio do desenvolvimento e do bemestar em âmbito nacional" (redação dada pela Emenda Constitucional n. 53, de 2006).

A alteração, aparentemente pontual, é significativa, à medida que substitui a força de uma lei complementar por várias leis, cujas proposições estabelecem marco regulatório para a efetiva cooperação entre os entes federados, buscando garantir o equilíbrio do desenvolvimento e do bem-estar em âmbito nacional. A concepção de equilíbrio e garantias de âmbito nacional sinaliza para o esforço federativo a ser efetivado. As bases da cooperação implicam, portanto, garantir as prerrogativas de autonomia dos entes federados e, paradoxalmente, a necessidade de mecanismos regulatórios direcionados ao bem-estar nacional. Tais questões traduzem uma tensão salutar entre a ação dos entes federados, incluindo a coordenação das políticas nacionais e os processos de descentralização. 
Assim, a CF de 1988 delineia, objetivamente, as bases da República Federativa do Brasil, ao afirmar que:

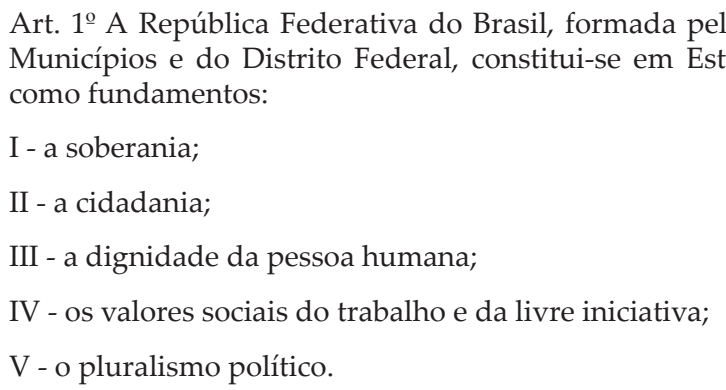

Essa união indissolúvel entre os entes federados se efetiva na complexa relação de coordenação e autonomia, para garantir, a todos, os direitos sociais, entre eles a educação. Assim, prevalece a perspectiva de superação dos problemas nacionais, por meio da superação da pobreza, da redução das assimetrias sociais e regionais, bem como da promoção do bem de todos, como base para o exercício da autonomia dos entes federados. Essa perspectiva é ratificada pelo artigo $3^{\circ} \mathrm{da} C \mathrm{~F}$, que ressalta os objetivos da República Federativa do Brasil:

Art. $3^{\circ}$ Constituem objetivos fundamentais da República Federativa do Brasil:

I - construir uma sociedade livre, justa e solidária;

II - garantir o desenvolvimento nacional;

III - erradicar a pobreza e a marginalização e reduzir as desigualdades sociais e regionais;

IV - promover o bem de todos, sem preconceitos de origem, raça, sexo, cor, idade e quaisquer outras formas de discriminação.

Isso revela o esforço nacional para a construção de uma sociedade cujas políticas, programas e ações tenham como convergência o bem comum, por meio da garantia de direitos sociais, o que requer um federalismo cooperativo, marcado pela descentralização e por padrões e diretrizes nacionais que assegurem o direito à educação com qualidade, o que implica combater as assimetrias regionais e sociais.

A educação é ratificada como direito social fundamental na CF: "Art. 6 São direitos sociais a educação, a saúde, a alimentação, o trabalho, a moradia, o lazer, a segurança, a previdência social, a proteção à maternidade e à infância, a assistência aos desamparados, na forma desta Constituição" (redação dada pela Emenda Constitucional n. 64, de 2010).

A educação está aliada a outras áreas estratégicas no alargamento dos direitos sociais, numa perspectiva cidadã, o que situa a compreensão basilar de federalismo, 
sinalizada pela CF. Isso tem implicações na relação entre os entes federados, sobretudo no que concerne à relação entre autonomias, direitos e responsabilidades, bem como as condicionalidades para o exercício efetivo das autonomias.

\section{O federalismo e o regime de colaboração e cooperação}

De que federalismo falamos? Como apreender suas bases constitutivas num cenário marcado por assimetrias de toda ordem, inclusive regionais, estaduais, municipais e locais? Qual o papel da União e dos governos subnacionais para o atendimento aos direitos sociais, com destaque para a educação?

Essas questões nos remetem à forma de organização territorial, ao modelo de desenvolvimento e planejamento do Estado brasileiro e aos limites estruturais à sua efetivação, requerendo, entre outras, uma ampla reforma tributária que contribua para a afirmação da autonomia dos governos subnacionais e, ao mesmo tempo, não prescinda do papel de coordenação nacional da União. No campo educacional, elas têm remetido à necessidade de instituição de um Sistema Nacional de Educação e de construção de planos decenais de educação como políticas de Estado, além das questões relativas ao regime de colaboração e cooperação entre os entes federados, sem negligenciar, paradoxalmente, as tensões e desafios que demarcam a definição das competências e o horizonte de suas autonomias.

Assim, entendo que a autonomia dos entes federados é ratificada, mas distingue-se de soberania, à medida que é definida nos termos da CF. Isso enseja uma reflexão ampla sobre a relação entre coordenação e autonomia, bem como a devida compreensão dos termos da $\mathrm{CF}$, para a atuação dos entes federados e para a efetivação do pacto federativo brasileiro.

Para compreender melhor este cenário, destacamos os artigos 18 e 22 da CF. Entendo que a autonomia vai sendo delineada, nos termos da CF, pelo estabelecimento de competências privativas, comuns, concorrentes, que possibilitam os elementos para compreender a República Federativa brasileira, ao tempo em que afirmam o necessário equilíbrio entre os entes federados, como prescrito no artigo 18 da CF. ${ }^{1}$

Nesse sentido, o artigo 22 define as competências privativas da União no campo da legislação, dentre as quais destaco o inciso XXIV - diretrizes e bases da educação nacional. $^{2}$

O artigo 23 estabelece, entre as competências comuns da União, dos estados, do Distrito Federal e dos municípios: "proporcionar os meios de acesso à cultura, à educação e à ciência (inc. V)". Ratificando e visando lograr êxito na efetivação dessa competência, traz como parágrafo único a fixação de leis complementares, para a 
cooperação entre os entes federados: "Leis complementares fixarão normas para a cooperação entre a União e os estados, o Distrito Federal e os municípios, tendo em vista o equilíbrio do desenvolvimento e do bem-estar em âmbito nacional" (redação dada pela Emenda Constitucional n. 53, de 2006).

É possível deduzir desses princípios constitucionais que proporcionar os meios de acesso à educação é dever de todos os entes federados e que sua efetivação deve ser resultante da cooperação e colaboração, o que não prescinde de normas nacionais, bem como de normas subnacionais articuladas, ou seja, o exercício da autonomia deve se efetivar no horizonte tensionado pelas condicionalidades e complementaridade, o que, no caso brasileiro, implica repensar o sistema tributário nacional e as condições objetivas dos entes federados nesse processo, por meio de uma reforma tributária que deslinde novos horizontes ao processo de descentralização das políticas.

O artigo 24, ao afirmar que "Compete à União, aos estados e ao Distrito Federal legislar concorrentemente, entre outros, sobre: [...] IX - educação, cultura, ensino e desporto", deslinda uma perspectiva e lógica política que se traduz num federalismo que se assenta em diretrizes e bases nacionais, sem prejuízo do papel de cada ente federado no tocante à sua autonomia.

Essa discussão nos remete à concepção de autonomia regulada, ou seja, a autonomia dos entes federados não é sinônimo de soberania, mas resultante da efetivação de bases de convergência demarcadas pela tensão entre as competências da União, sobretudo as privativas, e as competências comuns e concorrentes da União, estados, Distrito Federal e municípios. O papel da União é enfatizado e amplamente realçado como ente responsável pelo estabelecimento de normas gerais, cujo exercício não deve se efetivar por meio da perda de autonomia dos governos nacionais, como descrito nos parágrafos do artigo 24 transcritos a seguir:

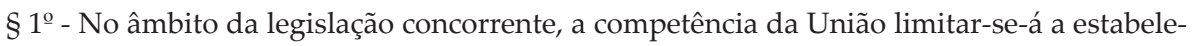
cer normas gerais.

$\S 2^{\mathrm{o}}$ - A competência da União para legislar sobre normas gerais não exclui a competência suplementar dos Estados.

$\S 3^{\mathrm{o}}$ - Inexistindo lei federal sobre normas gerais, os Estados exercerão a competência legislativa plena, para atender a suas peculiaridades.

$\S 4^{\circ}$ - A superveniência de lei federal sobre normas gerais suspende a eficácia da lei estadual, no que lhe for contrário.

Cruz (2012, p. 70), ao questionar a relação entre federalismo e descentralização como sinônimos e enfatizar os diferentes centros de poder, sinaliza que:

Embora haja essa diferenciação no papel de cada ente federado, a ideia tradicional de centralização e descentralização não se adéqua ao modelo federado, já que, segundo 
Bruno Théret (1998), a descentralização no federalismo implica descentralização qualificada, aquela que ocorre do governo federal para as unidades nas matérias que lhes são de competência própria, ou mesmo estejam no campo das prerrogativas comuns, sendo assegurado ao governo federal sua coordenação. Aqui se descentraliza o que já havia sido centralizado pela própria legislação, acordado no pacto fundante, ou seja, na Constituição Federal.

Os dispositivos constitucionais vão tecendo, desse modo, a dinâmica basilar do federalismo brasileiro e a necessidade de regulamentação da cooperação entre os entes federados, que, a despeito de gozarem de autonomia, contam com competências privativas, comuns e concorrentes, que não os descaracterizam, mas que devem se efetivar por meio de relações de cooperação, onde a dinâmica nacional de garantia de direitos se firma como diretriz. Esta, por sua vez, não secundariza a singularidade da ação dos entes federados, mas, ao contrário, fortalece tais ações, a partir de parâmetros nacionais de garantia dos direitos e do bem-estar nacional.

A CF estabelece as competências dos estados, Distrito Federal e municípios, a partir da observância aos termos nela dispostos, ao tempo em que reafirma as especificidades dos entes federados e sua respectiva autonomia. A questão que se coloca é como avançar para um federalismo cooperativo, no qual, aliado à coordenação federativa, não se efetive a centralização da União em detrimento da autonomia dos demais entes federados.

No capítulo III, seção I, referente à educação, a CF preconiza no artigo 211 que: "A União, os estados, o Distrito Federal e os municípios organizarão em regime de colaboração seus sistemas de ensino", com a finalidade de garantir o direito à educação para todos. Ratificando o papel de coordenação nacional da União, bem como as competências dos demais entes federados, é destacado que:

$\S 1^{\circ}$ A União organizará o sistema federal de ensino e o dos Territórios, financiará as instituições de ensino públicas federais e exercerá, em matéria educacional, função redistributiva e supletiva, de forma a garantir equalização de oportunidades educacionais e padrão mínimo de qualidade do ensino mediante assistência técnica e financeira aos estados, ao Distrito Federal e aos municípios. (Redação dada pela Emenda Constitucional n. 14, de 1996)

$\S 2^{\circ}$ Os municípios atuarão prioritariamente no ensino fundamental e na educação infantil. (Redação dada pela Emenda Constitucional n. 14, de 1996)

$\S 3^{\circ}$ Os estados e o Distrito Federal atuarão prioritariamente no ensino fundamental e médio. (Incluído pela Emenda Constitucional n. 14, de 1996)

$\S 4^{\circ} \mathrm{Na}$ organização de seus sistemas de ensino, a União, os estados, o Distrito Federal e os municípios definirão formas de colaboração, de modo a assegurar a universalização do ensino obrigatório. (Redação dada pela Emenda Constitucional n. 59, de 2009)

$\S 5^{\circ} \mathrm{A}$ educação básica pública atenderá prioritariamente ao ensino regular. (Incluído pela Emenda Constitucional n. 53, de 2006) 
Essas definições vão ao encontro da dinâmica federativa anteriormente afirmada e revelam que as ações de cooperação não prescindem da definição de padrões e diretrizes nacionais, de formas de colaboração entre os entes federados, em sintonia com as prerrogativas próprias de cada ente na efetivação do direito à educação.

Tais processos, considerando as emendas à $\mathrm{CF}$, demonstram a necessidade de estabelecer leis complementares que normatizem o regime de colaboração entre os entes federados. A CF, em seus artigos 23 e 211, revigorados pela EC n. 59/2009, avança no campo educacional, prevendo, inclusive, que as competências dos entes federados e a organização de seus sistemas de ensino devem se efetivar por meio de regime de colaboração.

A esse respeito, o Documento-Referência da Conae 2014 afirma que:

A CF/1988 define que compete à União e aos estados legislar concorrentemente em matéria educacional e, especificamente, à União compete estabelecer normas gerais, e, aos estados, DF e municípios, legislar sobre suas especificidades (art. 24). Isto implica a ação propositiva da União na definição de diretrizes, bases e normas gerais para a educação nacional, assim como a definição de normas específicas pelos estados e DF, aprovação de planos de educação e criação de sistemas educacionais pelos entes federados, em um cenário de efetivo regime de colaboração.

Nas atribuições de cada ente federado, a CF/1988 define que

[...] a União organizará o sistema federal de ensino e dos territórios, financiará as instituições de ensino públicas federais e exercerá, em matéria educacional, função redistributiva e supletiva, de forma a garantir equalização de oportunidades educacionais e padrão mínimo de qualidade do ensino mediante assistência técnica e financeira aos estados, ao Distrito Federal (DF) e aos municípios (EC n. 14/1996); os municípios atuarão prioritariamente no ensino fundamental e na educação infantil (EC n. 14/1996); os estados e o DF atuarão prioritariamente no ensino fundamental e médio (EC n. 14/1996).

Sobre o federalismo brasileiro há, portanto, algumas convergências, com realce para o entendimento de sua tipologia inédita, ao incluir os municípios com prerrogativas de autonomia e por caracterizar-se pelo binômio centralização/descentralização, assumindo importantes contornos na educação. Cruz (2012) sinaliza que o padrão de federalismo desenvolvido no Brasil também condiciona e influencia o setor educacional; o que é revelado pelas relações que a União estabelece com estados, Distrito Federal e municípios na gestão das políticas educacionais, embora a própria Constituição Federal defina parâmetros e responsabilidades, inclusive no financiamento da educação.

Nesse cenário, vários são os limites que demarcam a relação política entre o constituído e o constituinte do federalismo brasileiro, cuja égide ainda possui traços patrimoniais e a lógica de federalismo competitivo, em detrimento dos princípios 
constitucionais, que advogam um regime de colaboração entre os entes federados. Superar essas condições objetivas, articuladas à busca da redução das assimetrias regionais e sociais, constitui o grande desafio para o federalismo brasileiro e para a garantia de alargamento dos direitos sociais, inclusive o direito à educação.

No campo educacional, a superação desses limites tem ensejado a instituição do Sistema Nacional de Educação, planos decenais (nacional, estaduais, distrital e municipais) com vistas a garantir maior organicidade no acesso à educação em todos os níveis, etapas e modalidades, sobretudo na garantia à educação básica obrigatória (4 a 17 anos). Todos eles revelam um descompasso entre o marco jurídico normativo e os processos efetivos na relação entre os entes federados, o que ratifica a necessária regulamentação do regime de colaboração, sem prejuízo ao estabelecimento de relações de cooperação, onde haja uma relação proporcional entre competências e capacidade financeira, o que, no caso brasileiro, ensejará reformas de ordem estrutural, incluindo a reforma tributária.

\section{A organicidade das políticas educacionais}

Na área educacional têm-se vivenciado, nos últimos anos, medidas e tentativas de cooperação para buscar maior organicidade das políticas, programas e ações, sobretudo no financiamento da educação básica; a valorização, incluindo a formação, salário, carreira e condições de trabalho, de outro lado, ainda persiste a avaliação, fortemente marcada por testes estandardizados em detrimento de um sistema ou subsistema que articule variáveis com a perspectiva de desenvolvimento institucional. Trata-se de iniciativas definidas pela União, constituindo-se, em sua maioria, em processos com reduzida intervenção dos entes federados, mas que requerem sua adesão por meio de diversos mecanismos de indução financeira. Esse contexto, se não for revisto, poderá contribuir, cada vez mais, para a centralização do poder e para a consequente redução de autonomia dos governos subnacionais.

Em que pese os limites, as políticas e gestões direcionadas à educação básica vêm se processando, por meio de alterações substantivas, destacando-se, entre outros, a ruptura com a focalização no ensino fundamental; a aprovação do Fundeb (fundo de natureza contábil para toda a educação básica); o ensino fundamental de nove anos; a integração ensino médio e educação profissional; as novas definições para a educação infantil; o redirecionamento da educação especial/inclusiva; e as questões atinentes à diversidade, incluindo, neste contexto, etnia, gênero, orientação sexual e, mais recentemente, alterações por meio da Emenda Constitucional n. 09/2009, que, entre outras questões, ampliou a educação obrigatória (restrita ao ensino fundamental) para a educação dos 4 aos 17 anos, prevendo a universalização das etapas até 2016. Todas essas alterações têm implicações nas políticas e concepções direcionadas à educação básica. 
Apesar desses contornos, é fundamental discutir os limites dessas políticas conjunturais que, a despeito de potencializar a distribuição de recursos nos parâmetros nacionais, acabam, por vezes, se efetivando, sem a garantia de um regime de colaboração pautado na efetiva articulação e por meio de ações coordenadas entre os entes federados.

As políticas focalizadas no ensino fundamental, instituídas nos anos de 1990, são exemplo de medidas que mudaram as políticas de financiamento, mantidos os percentuais constitucionais vinculados, por meio da instituição do Fundef. Esse fundo, de natureza contábil, em conformidade com a CF e sob a tradição histórica de partição de responsabilidades entre as esferas federal, estaduais/distrital e municipais, no que concerne à definição de competências, alterou a lógica de financiamento sem, contudo, garantir um sistema descentralizado. ${ }^{3}$ Tratou-se de medida de grande impacto, que se consubstanciou como subvinculação de recursos direcionados a uma das etapas da educação básica - o ensino fundamental -, sem alterar estruturalmente o quadro tributário, ainda que tenha propiciado certa equalização de recursos para o ensino fundamental, a despeito do cenário assimétrico em que se constitui a educação nacional. Enfim, manteve-se a desigualdade estrutural entre recursos e responsabilidades entre os entes federados.

O Governo Lula implementou o Fundeb, cuja lógica política rompeu com a focalização anteriormente adotada, por meio da subvinculação para toda a educação básica, mantendo a natureza contábil do fundo e não avançando no real enfrentamento do custo aluno-qualidade das etapas e modalidades da educação básica.

A respeito do Fundeb, Davies (2006) alerta para os riscos das políticas de fundos no tocante a agravarem a fragmentação escolar, privilegiarem um nível de ensino, o foco em parte das receitas dos governos e, ainda, possibilidade de corporativismo dos profissionais da educação. A lógica é mantida no Fundeb, na medida em que este fundo, embora se direcione para toda a educação básica, incluindo etapas e modalidades, "define um percentual (pelo menos 60\%) só para os profissionais do magistério da educação básica, não mencionando os demais trabalhadores da educação (funcionários das escolas)" (DAVIES, op. cit., p. 53).

Essas reflexões expõem os avanços dos fundos, especialmente do Fundeb, mas, ao mesmo tempo, sinalizam para a sua fragilidade, ao não garantirem mudanças mais estruturais na superação das assimetrias da educação brasileira. Na valorização dos profissionais efetivam-se grandes esforços e dinâmicas de cooperação, com limites estruturais, devido à relação entre os entes federados e a lógica das políticas, sem avançar num efetivo pacto federativo, por meio da indução pelo financiamento.

Merecem ser ressaltados, entre outros, a institucionalização de Comitês Estratégicos da Política Nacional de Formação Inicial e Continuada dos Profissionais da 
Educação, a rede nacional de formação de professores, o piso salarial profissional nacional do magistério público na educação básica (Lei n. 11.738, de 16 de julho de 2008), a definição dos profissionais da educação, bem como a busca de organicidade por parte dos conselhos de educação, especialmente do Conselho Nacional de Educação (CNE). O CNE, por meio do Conselho Pleno, da Câmara da Educação Superior e da Câmara da Educação Básica, aprovou várias diretrizes, resoluções e pareceres, direta ou indiretamente articulados à formação de professores.

Os aparatos normativos do CNE, as políticas, ações e os programas do MEC, da Capes, bem como do Inep e FNDE, nem sempre foram guiados por organicidade nas bases formativas e concepções norteadoras, mas têm forte incidência nos governos subnacionais, em muitos casos, secundarizando sua autonomia face à centralidade conferida à União e à proposição e materialização de padrões e diretrizes nacionais.

O conjunto de aparatos normativos sobre a formação de professores indicou a necessidade de consolidação da legislação, resultando na constituição da Comissão Bicameral do $\mathrm{CNE},{ }^{4}$ indicando sua complexidade, os desdobramentos na coordenação federativa e a necessidade de regulamentação do regime de colaboração.

A avaliação da educação básica, marcada por vários mecanismos, provas e índices, não se estrutura como um subsistema orgânico, mas se traduz na superposição de ações e em instrumento de monitoramento da educação, em sua maioria por meio de políticas e ações propostas e coordenadas pela União, sem a efetiva relação de cooperação com os demais entes federados.

Ao debater a avaliação, o Documento da Conae registra a necessidade de um sistema nacional de avaliação da educação básica indutor de desenvolvimento institucional, que não se reduza à aferição do rendimento do estudante e do desempenho do sistema subordinados à lógica regulatória do Estado. Há concepções de avaliação conflitantes, o que requer uma ampla discussão sobre os fundamentos, a legitimidade, as finalidades, os instrumentos e a materialização de uma concepção que resulte do esforço e da cooperação entre os entes federados, constituindo-se, assim, em expressão do planejamento e efetivação de políticas, na construção coletiva e partilhada entre eles, em consonância com as orientações constitucionais, que indicam a relação entre avaliação e qualidade, gestão democrática, o papel dos sistemas, incluindo o Sistema Nacional de Educação, que abarcaria subsistemas, tais como financiamento, avaliação e valorização.

$\mathrm{Na}$ área educacional, esses processos ganham magnitude tendo em vista os desafios na democratização do acesso, garantia de permanência e qualidade da educação, em seus diferentes níveis, etapas e modalidades, ensejando, entre outros, a efetiva regulamentação do regime de colaboração, os planos de educação como políticas de Estado e a instituição do Sistema Nacional de Educação. 


\section{O direito à educação básica de qualidade}

O direito à educação básica de qualidade constitui um grande desafio para o Estado brasileiro e se explicita por indicadores educacionais, demarcados por assimetrias regionais, estaduais e municipais que requerem um novo esforço e um pacto federativo assentado na efetiva coordenação e cooperação, para a maior organicidade entre os processos, as políticas e programas educacionais, a gestão e o financiamento, e para a democratização da organização e gestão educacional, incluindo a ampliação do direito e a regulação.

Dentre os indicadores educacionais, destacam-se as taxas de matrícula líquida e bruta, bem como os anos de estudo da população, que, no caso brasileiro, possuem grandes assimetrias e acumulam enormes desafios para fazer avançar o acesso e a permanência com qualidade aos diferentes níveis, etapas e modalidades da educação.

Os indicadores de taxas de escolarização bruta e líquida da educação básica brasileira retratam as disparidades regionais, sobretudo na pré-escola e no ensino médio, que, em razão da EC n. 59/09, passam a fazer parte da educação básica obrigatória e devem ser universalizados até 2016. Tais processos resultam de questões macroestruturais, na medida em que, juntamente com as assimetrias regionais, há as disparidades sociais do modelo de desenvolvimento, envolvendo a distribuição de renda e a reforma tributária, aliadas à necessidade de regulamentar o regime de colaboração entre os entes federados, como condição para a consolidação de novos parâmetros de acesso à educação básica obrigatória.

\section{Tabela 1}

Taxas de escolarização bruta e líquida - Brasil (2011)

\begin{tabular}{|l|l|l|l|l|l|l|}
\hline \multirow{2}{*}{$\begin{array}{l}\text { Unidade da } \\
\text { Federação }\end{array}$} & \multicolumn{2}{|c|}{$\begin{array}{c}\text { Pré-escola } \\
(4 \text { e } 5 \text { anos) }\end{array}$} & \multicolumn{2}{c|}{$\begin{array}{c}\text { Ensino fundamental } \\
(6 \text { a 14 anos) }\end{array}$} & \multicolumn{2}{c|}{$\begin{array}{r}\text { Ensino médio } \\
(15 \text { a 17 anos) }\end{array}$} \\
\cline { 2 - 7 } & Bruta & Líquida & Bruta & Líquida & Bruta & Líquida \\
\hline Brasil & 69,7 & 54,2 & 106,9 & 91,9 & 82,2 & 51,6 \\
\hline Norte & 60,0 & 45,5 & 110,1 & 90,0 & 79,8 & 41,2 \\
\hline Nordeste & 77,0 & 59,8 & 111,0 & 90,8 & 77,9 & 42,6 \\
\hline Sudeste & 72,4 & 57,6 & 103,9 & 93,0 & 85,3 & 59,6 \\
\hline Sul & 58,9 & 43,8 & 104,6 & 92,5 & 80,4 & 55,1 \\
\hline Centro-Oeste & 57,5 & 44,5 & 105,6 & 92,2 & 91,5 & 56,8 \\
\hline
\end{tabular}

Fonte: IBGE/PNAD; elaborado por Inep/DTDIE. 
A despeito do cenário de desigualdades no campo educativo, alguns avanços nos marcos jurídico-normativos vêm sendo objeto de discussão e deliberação, desde a promulgação da CF de 1988, LDB, PNE. Ressalta-se a busca de novo marco de interdependência federativa e as medidas para efetivá-lo, considerando a necessária superação da desigualdade entre os entes federados sem prescindir do papel da União na proposição de políticas, padrões e diretrizes nacionais.

Mais recentemente, houve novos processos instituintes a partir da criação do PDE (2007), ${ }^{5}$ das avaliações e discussões sobre o PNE e, sobretudo, pela realização de conferências educacionais, com o protagonismo da Conae. Como desdobramento desses processos destacam-se, mais recentemente, as discussões e proposições sobre a necessidade de um Sistema Nacional de Educação. Essas discussões têm fomentado a retomada da instituição desse Sistema e a aprovação de lei complementar que regulamenta o regime de colaboração, bem como iniciativas para a ampliação de mecanismos de cooperação e de coordenação entre os entes federados.

Um complexo debate envolve questões diversas, como os Arranjos de Desenvolvimento Educacionais (ADE) e a discussão sobre os consórcios públicos em educação, bem como a necessidade de regulamentação do regime de colaboração. Essas questões têm incidência direta para sua proposição e, sobretudo, sua efetivação, no uso do fundo público e no embate travado entre esfera pública e esfera privada no campo das políticas públicas. Ressaltem-se, entre outros, os pareceres aprovados pelo Conselho Nacional de Educação (CNE) sobre ADE (Parecer CNE/CEB n. 9/2011 e Resolução CNE/CEB n. 1/2012) e regime de colaboração (Parecer CNE/CP n. 11/2012), a criação de GT no MEC, com a ampla participação, e as iniciativas de consolidação da Secretaria de Articulação dos Sistemas de Ensino (Sase) ${ }^{6}$ de discutir e instituir diretrizes nacionais para o debate.

Há que destacar os embates de concepções e estratégias de articulação e cooperação entre os entes federados. O Grupo de Trabalho constituído pelo MEC, por meio da Portaria n. 1238/2012, expressa essas tensões, na medida em que foi constituído para elaborar estudos sobre a implementação do regime de colaboração mediante os arranjos de desenvolvimento da educação, e em decorrência dos estudos e debates vai rediscutindo a orientação dos $\mathrm{ADE}^{7} \mathrm{e}$ sinalizando para perspectivas mais amplas, como os consórcios públicos, além de questões e proposições direcionadas à instituição de lei complementar de regulamentação do regime de colaboração.

O CNE aprovou pareceres sobre a organicidade na concepção de federalismo, coordenação federativa e regime de colaboração, traduzindo a complexa seara da constituição de um federalismo cooperativo em educação, os dilemas, as disputas de concepções e sua compreensão sobre ações de cooperação e colaboração entre e com os entes federados. De todo modo, esses movimentos vão traduzindo esforços, 
embates e concepções em disputa, no campo educativo, mas que convergem na busca de estratégias de colaboração e cooperação, em um cenário em que não ocorreu a aprovação de lei complementar sobre regime de colaboração.

Abrúcio (2010) destaca, ainda, o estabelecimento de mecanismos de coordenação intergovernamental, por intermédio de normas com validade nacional, mostrando o exemplo do piso do magistério. O autor ressalta a predominância das ações procedentes da União e a necessidade de um papel mais ativo dos estados, para gerar maior equilíbrio governamental.

A respeito desse processo, o Documento-Referência da Conae 2014 sinaliza:

É fundamental o pacto federativo, construído na colaboração e coordenação entre os entes federados e sistemas de ensino, em prol da garantia do direito à educação de qualidade para todos. Ou seja, a coordenação e a cooperação federativa, fruto da organização territorial e política, caracterizada pela distribuição de responsabilidades e repartição de competências (concorrentes e comuns), bem como das políticas nacionais e da descentralização, como definido pela CF/1988, devem constituir a base do regime de colaboração e, no campo educacional, das diretrizes da União e dos demais entes federados (estados, Distrito Federal e municípios).

Tais discussões e proposições ratificam o Documento da Conae 2014, ao afirmar que

[...] "a organização e regulação da educação nacional deve garantir a articulação entre acesso, permanência, ${ }^{8}$ valorização dos profissionais, gestão democrática, padrão de qualidade, piso salarial profissional por meio dos seguintes princípios: I - igualdade de condições para o acesso e permanência na escola; II - liberdade de aprender, ensinar, pesquisar e divulgar o pensamento, a arte e o saber; III - pluralismo de ideias e de concepções pedagógicas, coexistência de instituições públicas e privadas de ensino; IV - gratuidade do ensino público em estabelecimentos oficiais; V - valorização dos profissionais da educação escolar, garantidos, na forma da lei, planos de carreira, com ingresso exclusivamente por concurso público de provas e títulos aos das redes públicas (EC n. 53/2006); VI - gestão democrática do ensino público, na forma da lei; VII - garantia de padrão de qualidade; VIII - piso salarial profissional nacional para os profissionais da educação escolar pública, nos termos de lei federal (EC n. 53/2006). Parágrafo único. A lei disporá sobre as categorias de trabalhadores considerados profissionais da educação básica e sobre a fixação de prazo para a elaboração ou adequação de seus planos de carreira, no âmbito da União, dos estados, do DF e dos municípios (EC n. 53/2006).

A definição de formas de colaboração entre os sistemas de ensino e a fixação de normas de cooperação entre os entes federados são fundamentais para a garantia da universalização da educação obrigatória de 4 a 17 anos. Isso pressupõe um tensionamento à diferenciação que marca o sistema federativo, bem como a relação entre descentralização e centralização como caminho fértil para a garantia do direito à educação para todos, o que se reafirma no incremento de ações interfederativas 
construídas de forma participativa. Isso caracterizaria as bases de uma concepção e lógica de gestão pautada pela interdependência.

A esse respeito, Marques et al. (2013) afimam que:

Pelo menos seis aspectos devem estar presentes no debate de um modelo de gestão pautado pela interdependência: (i) o papel central da União na indução da qualidade na educação básica; (ii) a autonomia dos estados e municípios para a gestão dos seus sistemas; (iii) o modelo de financiamento capaz de assegurar um padrão nacional de qualidade; (iv) o planejamento decenal articulado entre as três esferas de governo; (v) a valorização dos profissionais da educação; e (vi) o alinhamento entre currículo, formação de professores e avaliação de aprendizagem.

É preciso garantir condições para que as políticas educacionais, concebidas e implementadas de forma articulada entre os sistemas de ensino, promovam formação integral, por meio da garantia da universalização, da expansão e da democratização, com qualidade, da educação básica e superior; consolidação da pós-graduação e da pesquisa científica e tecnológica; educação inclusiva, reconhecimento e valorização da diversidade; avaliação educacional emancipatória; definição de parâmetros e diretrizes para a valorização dos profissionais da educação; gestão democrática.

Nessa direção, o Documento-Referência da Conae avança, ao propor que:

A consolidação de um SNE que articule os diversos níveis e esferas da educação nacional não pode ser realizada sem considerar os princípios assinalados, bem como a urgente necessidade de superação das desigualdades sociais, étnico-raciais, de gênero e relativas à diversidade sexual ainda presentes na sociedade e na escola. Isso só será possível por meio do debate público e da consonância entre Estado, instituições de educação básica e superior e movimentos sociais, em prol de uma sociedade democrática, direcionada à participação e à inclusão, sobretudo pela articulação com diferentes instituições, movimentos sociais, com o Fórum Nacional de Educação (FNE), o Conselho Nacional de Educação (CNE), conselhos estaduais, distrital e municipais de educação e conselhos escolares com ampla participação popular.

Outra definição crucial para as políticas e para o planejamento da educação no Brasil foi enfatizada na redação da EC n. 59/2009, ao indicar que uma lei específica estabeleceria o PNE, de duração decenal, com o objetivo de articular o SNE, em regime de colaboração entre os entes federados, definindo diretrizes, objetivos, metas e estratégias de implementação, para assegurar a manutenção e desenvolvimento do ensino em seus diversos níveis, etapas e modalidades, por meio de ações integradas dos poderes públicos das diferentes esferas federativas, incluindo o estabelecimento de meta de aplicação de recursos públicos em educação como proporção do produto interno bruto (PIB). A efetivação do SNE tem como pressuposto o disposto da $\mathrm{CF} / 1988$, segundo o qual compete privativamente à União legislar sobre diretrizes e bases da educação nacional (art. 22). 


\section{SNE: desafios à constituição e instituição}

Nesse cenário, é fundamental avançar na construção/efetivação do Sistema Nacional de Educação (SNE). O que entendemos por SNE? Por que se faz necessário instituí-lo? O que um SNE inovaria em matéria educacional?

Essas questões são complexas e requerem exame minucioso. Num primeiro momento, é fundamental situar os embates e disputas nessa arena, indo desde a concepção, abrangência, composição e finalidades até a compreensão de que temos um sistema de fato, ainda que não assentado em sólidas bases jurídicas. Nesse debate, entendo que o SNE não está instituído, ainda que tenhamos diretrizes e bases da educação nacional e a organização de sistemas de ensino, entre outros. Há uma relação direta e intrínseca entre PNE, SNE, regime de colaboração e, nesse sentido, é fundamental avançar nas orientações jurídico-normativas, envolvendo a aprovação de um PNE como política de Estado, bem como a lei complementar do regime de colaboração, como passos concomitantes à instituição do SNE, cujas bases constitutivas nos remetem ao delineamento de medidas de coordenação federativa articulado à normatização dos processos de decisão e responsabilidades compartilhadas entre os entes federativos, a partir da efetivação da já denominada descentralização qualificada.

Essa discussão nos remete às bases de um sistema de educação. A esse respeito, destaco quatro elementos fundamentais ressaltados por Cury (2010, p. 164) ao assinalar que:

Um sistema de educação supõe, como definição, uma rede de órgãos, instituições escolares e de estabelecimentos - fato; um ordenamento jurídico com leis de educação - norma; uma finalidade comum - valor; uma base comum - direito.

Esses quatro elementos devem coexistir como conjunto, como conjunto organizado, como conjunto organizado sob um ordenamento, como conjunto organizado sob um ordenamento com finalidade comum (valor), como conjunto organizado sob um ordenamento com finalidade comum (valor) sob a figura de um direito.

Essa coexistência supõe unidade e diversidade sem antinomias (ausência de incompatibilidades normativas)

Abicalil (2012, p. 24), ao discutir a temática, apresenta contribuição extremamente relevante, a partir de diálogos com vários teóricos, ratificando a necessidade de instituição do SNE e dos desdobramentos desse processo, ao destacar que:

Igualmente, é imperativo resguardar o conceito de SNE com as características intrínsecas ao seu caráter ontológico, essencialmente público e unitário, considerada a variedade de seus elementos e a sua unidade coerente e operante (SAVIANI, 2011) [...]. Além disso, ainda que concordemos que o objeto central da disputa para a implantação do 
SNE esteja menos na formação de organização e mais na concepção de educação (GRACINDO, 2010), [...] impõe-se a atenção em relação ao vigor do movimento social e ao rigor da lei na formulação da política [...]. Ganham destaque, por outro lado, as formulações de avanço na composição de instâncias interfederativas de decisão, formulação e decisão operacional (ABRUCIO, 2010) - mais visível como pleito e inovação no nível da educação básica (MARTINS, 2011) - e de controle, acompanhamento e participação democrática. No entanto, além das medidas de coordenação federativa, necessário se faz avançar na normatização das responsabilidades compartilhadas entre os entes federados (ARAUJO, 2010), assim como na retomada de iniciativas de políticas nacionais que resguardem o protagonismo da ação pública (BALDIJÃO; TEIXEIRA, 2011) e as novas e ampliadas dimensões, para enfeixar - em perspectiva - os ordenadores do financiamento e da democratização da gestão da educação no PNE. (DOURADO; AMARAL, 2011)

A compreensão das bases de instituição do SNE no Documento-Referência da Conae 2014 é singular, pois este sistema "é entendido como expressão institucional do esforço organizado, autônomo e permanente do Estado e da sociedade, compreendendo os sistemas de ensino da União, dos estados, do Distrito Federal e dos municípios, bem como outras instituições públicas ou privadas de natureza educacional".

Dada a complexa dinâmica do Estado brasileiro e a persistência de marcas de patrimonialismo e clientelismo, é fundamental a compreensão de que o momento instituinte atual deve considerar os avanços conquistados, as instâncias efetivadas, as formas de colaboração já regulamentadas, bem como o questionamento de seus limites e simulacros, em sintonia com novos marcos, resultantes de processos de gestão democrática e participativa, sem negligenciar a complexidade que marca o federalismo e suas potencialidades. A esse respeito, Abrúcio (2010, p. 42-43) sinaliza que:

A opção pelo federalismo significa, em grande medida, uma complexificação tanto do processo decisório como de sua legitimação, uma vez que cresce o número de atores e de arenas capazes de definir os rumos da ação coletiva. Tal conformação institucional contém potencialidades democráticas, como a aproximação dos governos de suas comunidades (pela via da descentralização), o respeito às peculiaridades regionais dentro de uma nação e a adoção do princípio da barganha e da negociação como balizadores do processo político. Entretanto, do mesmo modo, podem surgir problemas advindos dessa forma de Estado, como a dificuldade em conciliar os interesses locais com os gerais e a necessidade de coordenar diversos esforços intergovernamentais para atuar numa mesma política, num jogo que não é naturalmente cooperativo. Na verdade, a dinâmica federativa muitas vezes pode ser marcada pela falta de clareza sobre a responsabilidade dos entes; em outras, pela competição desmedida entre os níveis de governo.

A compreensão da complexidade do federalismo brasileiro é vital, sobretudo se se pretende que seja estabelecido o SNE como forma de organização que viabilize o alcance dos fins da educação, em sintonia com o estatuto constitucional do regime de colaboração entre os sistemas de ensino (federal, estadual, distrital e municipal), 
tornando viável o que é comum às esferas do poder público (União, estados, Distrito Federal e municípios): a garantia de acesso à cultura, à educação e à ciência (art. 23, inciso V).

FRUTUOSO (2010, p. 103), ao analisar avanços e desafios do Sistema Único de Saúde (SUS), sugere pistas para a institucionalização do SNE, destacando a vitalidade do SUS a partir da relação articulada entre descentralização das ações, gestão colegiada pactuada e gestão tripartite.

A descentralização das ações, a relação colegiada pactuada e o financiamento tripartite, incluindo repasse regular e automático com a utilização dos recursos com base em planos aprovados e fiscalizados pelas instâncias de controle social, são mecanismos que podem fortalecer uma gestão com foco nas necessidades dos cidadãos e orientada para resultados. Implantando mecanismos de gestão, gerenciamento, acompanhamento e avaliação de resultados, democráticos e transparentes, a administração pública ganhará a eficiência necessária para garantir os direitos constitucionais a toda sociedade brasileira.

Considerando essa relação e as bases constitucionais, o PNE assume grande centralidade na institucionalização do SNE. O projeto em tramitação, a despeito de seus limites estruturais, sobretudo na concepção de avaliação e gestão, bem como no uso do fundo público, avança na defesa de princípios basilares da organização, gestão e planejamento das políticas no Brasil e, consequentemente, da institucionalização do SNE, orientado pelas seguintes diretrizes:

I - promoção da alfabetização;

II - universalização do atendimento escolar;

III - superação das desigualdades educacionais, com ênfase na promoção da igualdade racial, regional, de gênero e de orientação sexual, e na garantia de acessibilidade;

IV - melhoria da qualidade da educação;

V - formação para o trabalho e para a cidadania;

VI - promoção do princípio da gestão democrática da educação;

VII - promoção humanística, científica, cultural e tecnológica do País;

VIII - estabelecimento de meta de aplicação de recursos públicos em educação como proporção do produto interno bruto, que assegure atendimento às necessidades de expansão, com padrão de qualidade e equidade;

IX - valorização dos (as) profissionais da educação;

$\mathrm{X}$ - promoção dos princípios do respeito aos direitos humanos, à diversidade e à sustentabilidade socioambiental.

Em sintonia com essas diretrizes, o Documento-Referência da Conae traz importantes contribuições para a instituição do SNE, ao afirmar que: 
Para garantir o direito à educação, em sintonia com diretrizes nacionais, a construção de um SNE requer, portanto, o redimensionamento da ação dos entes federados, garantindo diretrizes educacionais comuns em todo o território nacional, tendo como perspectiva a superação das desigualdades regionais e a garantia do direito à educação de qualidade. Dessa forma, objetiva-se o desenvolvimento de políticas públicas educacionais nacionais universalizáveis, por meio da regulamentação das atribuições específicas de cada ente federado no regime de colaboração e da educação privada pelos órgãos de Estado.

Assim, compete às instâncias do SNE definir e garantir finalidades, diretrizes e estratégias educacionais comuns, sem prejuízo das especificidades de cada sistema, e assumir a articulação, normatização, coordenação e regulamentação da educação nacional pública e privada. Em tal sistema, os conselhos nacional, estaduais, distrital e municipais, organizados com a garantia de gestão democrática, são fundamentais para a supervisão e manutenção das finalidades, diretrizes e estratégias comuns. O processo deve garantir a consolidação dos fóruns nacional, estaduais, distrital e municipais de educação, em articulação com os respectivos sistemas de ensino e conselhos equivalentes.

Nesta ótica, entendo que a articulação entre o PNE e o SNE, compreendidos como políticas de Estado, deve-se direcionar à garantia do direito à educação, envolvendo as diferentes esferas de governo e os sistemas de ensino no atendimento à população, em todos os níveis, etapas e modalidades de educação, em regime de corresponsabilidade, onde haja organicidade entre a capacidade financeira e as respectivas responsabilidades de cada ente federado, sem prejuízo das competências comuns e supletivas, tendo por eixo a definição da EC 59/2009 que estabelece que o SNE em regime de colaboração deve ser articulado sob o PNE.

Um grande desafio colocado ao Estado Brasileiro consiste em definir e garantir as diretrizes e bases para a(s) lei(s) complementar(es) em consonância ao cumprimento do artigo 23 da CF, parágrafo único. Nessa direção, a instituição do SNE é um passo fundamental. Visando delinear a instituição do SNE e indicar um regime de colaboração entre os entes federados, o Documento-Referência da Conae 2014 vaticina que:

Para a existência do SNE, é fundamental que os órgãos legislativos e executivos dos entes federados estabeleçam políticas educacionais, traduzidas em diretrizes e estratégias nacionais, planos nacionais, programas e projetos, coordenando e apoiando técnica e financeiramente, de forma suplementar, as ações dos diversos sistemas de ensino, para alcançar os objetivos da educação nacional, auxiliados por um órgão normatizador de Estado (CNE), que garanta a unidade na diferença. O fortalecimento da ação dos fóruns de educação (nacional, estaduais, distrital e municipais), bem como a instituição periódica de conferências de educação (nacional, estaduais, distrital e municipais) são passos necessários à proposição e deliberação coletiva na área educacional e à maior organicidade dos sistemas de ensino.

Em consonância com a legislação vigente, a construção do SNE poderá propiciar organicidade e articulação à proposição e materialização das políticas educativas, por meio de esforço integrado e colaborativo, a fim de consolidar novas bases na relação entre os entes federados, para garantir o direito à educação e à escola de qualidade social. Diante do pacto federativo, a instituição do SNE deve respeitar a autonomia já construída pelos 
sistemas de ensino. Quanto à educação privada, deve ser regulada pelos órgãos de Estado, obedecendo às regras e normas determinadas pelo SNE.

Para superar as assimetrias regionais e sociais, é preciso reiterar que a regulamentação do regime de colaboração, por meio de lei complementar, deve enfatizar um federalismo marcado por ações coordenadas e, sobretudo, por cooperação técnica e financeira entre os entes federados, com especial ênfase ao papel da União. O Documento indica a necessidade de explicitação desse papel, ao afirmar que é fundamental:

[...] explicitar a participação da União na cooperação técnica e, especialmente, na determinação de transferências regulares e contínuas de recursos financeiros às instituições públicas dos estados, DF e municípios, priorizando os entes federados com baixos índices de desenvolvimento socioeconômico e educacional, indicando os que mais demandam apoio para a garantia do custo aluno-qualidade (CAQ). Essa regulamentação deve prever meios de superação das desigualdades regionais, especialmente pela construção de uma política de financiamento ancorada na perspectiva de qualidade para a educação básica e superior.

\section{Considerações finais}

Ao longo do texto, fui situando os limites e simulacros ao federalismo brasileiro e, sobretudo, os desafios às políticas educacionais e seus desdobramentos na relação entre os entes federados e a democratização do acesso à educação básica, num cenário de grandes assimetrias regionais e desigualdades sociais.

As análises revelam a dificuldade de se avançar para um federalismo de cooperação na educação, balizado por processos de descentralização e autonomia dos entes federados e de coordenação federativa, que garantam diretrizes e padrões de qualidade nacional para a educação. Isto implica defender a noção de descentralização qualificada, onde a coordenação federativa não se traduz em centralização por parte da União, mas é resultante de esforços de cooperação e colaboração entre os entes federados, que, desse modo, não prescindem de diretrizes e padrões de qualidade nacional ao participarem de sua proposição e materialização.

Outro aspecto foi a análise das atuais estratégicas de cooperação e colaboração e de seus limites e simulacros, requerendo, em sintonia com os preceitos constitucionais (art. 23 da CF), a discussão e proposição de lei(s) complementar(es) que regulamente $(\mathrm{m})$ o regime de colaboração e, de modo concomitante, de estratégias que contribuam para o estabelecimento de espaços interfederativos de discussão e proposição de políticas, programas e ações, diante dos grandes desafios da educação básica, em particular no que concerne à universalização da educação básica obrigatória (4 a 17 anos) até 2016, sob um horizonte de responsabilidade e de autonomia dos entes federados. Além dessas questões, do ponto de vista mais estrutural, 
é fundamental uma reforma tributária para o fortalecimento dos entes federados no cumprimento de suas competências.

Esses eixos são importantes para a compreensão do complexo cenário do federalismo atual, para a proposição de um novo marco na relação entre os entes federados, com vistas à instituição de um federalismo cooperativo em educação, que hoje enseja avanços em direção à aprovação do PNE e à instituição do SNE como políticas de Estado e a garantia do direito a educação, motivando novos marcos à qualidade da educação, aos processos de avaliação, valorização dos profissionais e financiamento.

Desse modo, buscaram-se elementos para a construção das diretrizes e bases para a coordenação federativa pautada na gestão democrática e participativa, ao tempo em que se procuram novos patamares à articulação entre os entes federados, o que implica o fortalecimento de instâncias, fóruns federativos e comissões, numa perspectiva de fortalecimento dos governos subnacionais e, paradoxalmente, da coordenação federativa, sob novas bases.

Esses são os desafios que se colocam para o Estado brasileiro com a tramitação do PNE no Senado Federal, cujo relatório caracterizou-se por um significativo recuo ao eliminar a meta intermediária dos percentuais do PIB para a educação e, sobretudo, ao propor o redirecionamento do fundo público de investimento direto para o setor público (para uma compreensão de investimento público total, naturalizando a possibilidade de repasses para o setor privado).

Paradoxalmente, estamos vivenciando um importante momento instituinte das conferências preparatórias à Conae/2014 com ampla participação. E, ainda, é importante destacar que após as amplas mobilizações sociais, em junho de 2013, nas grandes e médias cidades brasileiras, vimos prosperar algumas tomadas de decisões pelos poderes constituídos, ressaltando, em particular, o avanço que representou a aprovação do projeto de lei na Câmara para a destinação dos royalties do petróleo para a saúde e a educação, que garantirá a esta, se aprovado também no Senado, cerca de dez vezes o valor que estava previsto no texto original, com profundos impactos à educação nacional.

É nesse cenário complexo que se situa a instituição do SNE, a aprovação do PNE e os desdobramentos no que concerne à construção de um federalismo cooperativo em educação.

\section{Notas}

1. "Art. 18. A organização político-administrativa da República Federativa do Brasil compreende a União, os Estados, o Distrito Federal e os Municípios, todos autônomos, nos termos desta Constituição". 
2. Importante destacar, no artigo 22, o "Parágrafo único. Lei complementar poderá autorizar os Estados a legislar sobre questões específicas das matérias relacionadas neste artigo". O parágrafo ratifica as competências privativas da União e, por meio de lei complementar, a possibilidade de os estados legislarem sobre questões especificadas, quando autorizados pela União.

3. O processo de descentralização é bastante complexo, envolvendo as diferentes esferas, os sistemas de ensino e as unidades educativas, bem como as políticas, programas e ações sobre a organização, gestão e financiamento da educação, num cenário marcado pela diversificação e diferenciação institucional e balizado por assimetrias regionais. A respeito da discussão, é fundamental avaliar os estudos de Casassus (1989) sobre descentralização e desconcentração na América Latina.

4. Esta Comissão, tendo em vista a complexidade da matéria, envolve o estudo de temáticas e concepções sobre a formação inicial e continuada, enfocando a busca de maior organicidade dos aparatos normativos do CNE em relação à formação em nível médio e superior; a programas especiais de formação pedagógica; à instituição de diretrizes curriculares nacionais; à formação continuada, entre outras.

5. A respeito da discussão sobre os limites do PDE, veja Saviani (2009) e Dourado (2010).

6. A Secretaria de Articulação com os Sistemas de Ensino (Sase), "criada pelo Decreto n. 7.480, de 16 de maio de 2011, tem atribuições específicas para apoiar o desenvolvimento de ações para a criação de um Sistema Nacional de Educação, aprofundando o regime de cooperação entre os entes federados; assistir e apoiar o Distrito Federal, os estados e municípios na elaboração, adequação, acompanhamento e avaliação democrática de seus Planos de Educação em consonância com o estabelecido no PNE, bem como no aperfeiçoamento dos processos de gestão na área educacional; promover a valorização dos profissionais da Educação, apoiando e estimulando a formação inicial e continuada, a estruturação da carreira e da remuneração e as relações democráticas de trabalho". Disponível em: $<$ http://portal.mec.gov.br/index.php?option=com_content\&view=article\&id=16778 \&Itemid=1125>. Acesso em: 12 abr. 2013.

7. A questão relativa aos Arranjos de Desenvolvimento Educacional merece análise pormenorizada, em outro artigo. Ela foi aqui destacada dada a capilaridade com que tem ocupado os debates e regulamentações (a exemplo: parecer CNE, criação do GT, inserção no PL do PNE, entre outros) e, sobretudo, no que concerne ao horizonte proposto, às concepções de federalismo e ação de cooperação e colaboração e as questões atinentes ao financiamento, relação entre esfera pública e esfera privada, entre outros. É fundamental discutir tais proposições e seus prováveis desdobramentos e implicações no campo.

8. Permanência entendida numa acepção ampla, envolvendo a garantia de aprendizagem e conclusão com sucesso pelo estudante.

\section{Referências}

ABICALIL, C.A. O federalismo e o Sistema Nacional de Educação: uma oportunidade fecunda. Retratos da Escola, Brasília, DF, v. 6, n. 10, p. 21-37, jan./jun. 2012. Disponível em: <http//www.esforce.org.br>

ABRÚCIO, F.L. A dinâmica federativa da educação brasileira: diagnóstico e propostas de aperfeiçoamento. In: OLIVEIRA, R.P.; SANTANA, W. (Org.). Educação e federalismo no Brasil: combater as desigualdades, garantir a diversidade. Brasília, DF: Unesco, 2010, p. 39-70.

ARAÚJO, G.C. Direito à educação básica. A cooperação entre os entes federados. Retratos da Escola, Brasília, DF, v. 4, n. 7, p. 231-241, jul./dez. 2012. Disponível em: $<$ http//www.esforce.org.br> 
BALDIJÃO, C.E; TEIXEIRA, Z. A. A educação no Governo Lula. São Paulo: Editora Perseu Abramo, 2011.

BRASIL. Câmara dos Deputados. Projeto de Lei n. 8.035, de 20 de dezembro de 2010. Aprova o Plano Nacional de Educação para o decênio 2011-2020 e dá outras providências. Brasília, DF: Câmara dos Deputados, 2010b. Disponível em: <http:// www.camara.gov.br/proposicoesWeb/fichadetramitacao?idProposicao=490116>. Acesso em: mar. 2013.

BRASIL. Ministério da Educação. Construindo o sistema nacional articulado de educação: o Plano Nacional de Educação, diretrizes e estratégias de ação; documento final da Conae 2010. Brasília, DF: MEC, 2010a. Disponível em: <http://conae.mec.gov.br/images/ stories/pdf/pdf/documetos/documento_final.pdf >. Acesso em: mar. 2013.

BRASIL. Ministério da Educação. Portaria n. 1.407, de 14 de dezembro de 2010. Institui o Fórum Nacional de Educação - FNE. Diário Oficial da União, Brasília, DF, 16 dez. 2010.

BRASIL. Ministério da Educação. O PNE na articulação do sistema nacional de educação: participação popular, cooperação federativa e regime de colaboração. Documentoreferência da Conae 2014. Brasília, DF: MEC, 2012. Disponível em: <http://fne.mec. gov.br/images/pdf/documentoreferenciaconae2014versaofinal.pdf $>$. Acesso em: mar. 2013.

CASTRO, J.A. Financiamento da educação pública no Brasil: evolução dos gastos. In: OLIVEIRA, R.P.; SANTANA, W. (Org.). Educação e federalismo no Brasil: combater as desigualdades, garantir a diversidade. Brasília, DF: Unesco, 2010. p. 169-190.

CONFEDERAÇÃO NACIONAL DOS TRABALHADORES EM EDUCAÇÃO (CNTE). Políticas e gestão da educação básica: concepções e proposições da CNTE. Brasília, DF: CNTE; Escola de Formação, 2013.

CUNHA, L.A. A educação carente de autonomia: regime federativo a serviço da religião. Retratos da Escola, Brasília, DF, v. 6, n. 10, p. 95-104, jan./jun. 2012. Disponível em: $<$ http//www.esforce.org.br $>$

CURY, C.R.J. Os desafios da construção de um Sistema Nacional de Educação. Disponível em: <http://conae.mec.gov.br/images/stories/pdf/jamil_cury.pdf>. Acesso em: 14 abr. 2013.

CURY, C.R.J. A questão federativa e a educação escolar. In: OLIVEIRA, R.P.; SANTANA, W. (Org.). Educação e federalismo no Brasil: combater as desigualdades, garantir a diversidade. Brasília, DF: Unesco, 2010. p. 149-168..

CRUZ, R.E. Federalismo e educação: um pacto a se rever. Retratos da Escola, Brasília, DF, v. 6, n. 10, p. 65-78, jan./jun. 2012. Disponível em : <http//www.esforce.org.br> 
DAVIES, N. A política de fundos no financiamento da educação. Fundeb: Solução ou remendo para o financiamento da educação básica? In: GOUVEIA, A.B.; SOUZA, A.R. Conversas sobre financiamento da educação no Brasil. Curitiba: UFPR, 2006. p. 43-70.

DOURADO, L.F. Avaliação do Plano Nacional de Educação 2001-2009: questões estruturais e conjunturais de uma política. Educação \& Sociedade, Campinas, v. 31, n. 112, p. 677-705, jul./set. 2010.

DOURADO, L.F. (Org.). Plano Nacional de Educação (2011-2020): avaliação e perspectivas. 2. ed. Goiânia: UFG; Belo Horizonte: Autêntica, 2011.

DOURADO, L.F.; AMARAL, N.C. Financiamento e gestão da educação e o PNE 2011-2020: avaliação e perspectivas. In: DOURADO, L.F. (Org.). Plano Nacional de Educação (2011-2020): avaliação e perspectivas. 2. ed. Goiânia: UFG; Belo Horizonte: Autêntica, 2011. p. 285-315.

FERNANDES, F.C. A Conferência Nacional de Educação: construção democrática de políticas de Estado. Disponível em: <http://conae.mec.gov.br/images/stories/pdf/ texto\%20chagas\%20alterado25.03.pdf>. Acesso em: 20 abr. 2013.

FREITAS, D.N.T. A avaliação da educação básica no Brasil. Campinas: Autores Associados, 2007.

FRUTUOSO, J. A gestão do Sistema Único de Saúde. In: OLIVEIRA, R.P.; SANTANA, W. (Org.). Educação e federalismo no Brasil: combater as desigualdades, garantir a diversidade. Brasília, DF: Unesco, 2010. p. 89-105.

GUANEM, E. Participação e regime de colaboração entre unidades federadas na educação brasileira. In: OLIVEIRA, R.P.; SANTANA, W. (Org.). Educação e federalismo no Brasil: combater as desigualdades, garantir a diversidade. Brasília, DF: Unesco, 2010. p. 191-211.

GRACINDO, R.V. Sistema Nacional de Educação e a escola pública de qualidade para todos. Retratos da Escola, Brasília, DF, v. 4, n. 6, p. 53-64, jan.jjun. 2010. Disponível em: $<\mathrm{http} / /$ www.esforce.org.br $>$

MARQUES. B. et al. O Sistema Nacional de Educação: em busca de consensos. Disponível em: <http://conae2014.mec.gov.br/images/pdf/marques_nogueira_lambertucci_grossi. pdf $>$. Acesso em: 20 abr. 2013.

MARTINS, P.S. Fundeb, federalismo e regime de colaboração. Campinas: Autores Associados, 2011.

OLIVEIRA, R.P. Direito à educação e federalismo no Brasil. Retratos da Escola, Brasília, DF, v. 6, n. 10, p. 39-47, jan./jun. 2012. Disponível em: <http//www.esforce.org.br> 
OLIVEIRA, R.P.; SOUSA, S.Z. Introdução. In: OLIVEIRA, R.P.; SANTANA, W. (Org.). Educação e federalismo no Brasil: combater as desigualdades, garantir a diversidade. Brasília, DF: Unesco, 2010. p. 13-38.

SANTOS, C.H.M. Notas sobre a necessidade de reformas no Sistema Tributário Nacional. In: CARNEIRO, R.M.; MATIJASCIC, M. (Org.). Desafios do desenvolvimento brasileiro. Brasília, DF: Ipea, 2011. p. 103-119.

SAVIANI, D. Sistema de Educação: subsídios para a Conferência Nacional de Educação. Disponível em: $<$ http://conae.mec.gov.br/images/stories/pdf/conae_dermevalsaviani. pdf $>$. Acesso em: 20 abr. 2013.

SAVIANI, D. Plano Nacional de Educação, a questão federativa e os municípios: o regime de colaboração e as perspectivas da educação brasileira. São Paulo: Fundação Grobis, 2010. Disponível em: <http://grabois.org.br/portal/revista.int.php?id_sessao=16\&id_ publicacao $=447 \& i d \_i n d i c e=2559>$

Recebido em 1ํo de julho de 2013.

Aprovado em 17 de julho de 2013. 